\title{
Time- and Temperature-Dependent Growth Behavior of Ionic Liquids on Au(111) Studied by Atomic Force Microscopy in Ultrahigh Vacuum
}

Manuel Meusel, Afra Gezmis, Simon Jaekel, Matthias Lexow, Andreas Bayer, Florian Maier, and Hans-Peter Steinrück*

Cite This: J. Phys. Chem. C 2021, 125, 20439-20449

Read Online

ABSTRACT: We deposited defined amounts of $\left[\mathrm{C}_{1} \mathrm{C}_{1} \operatorname{Im}\right]\left[\mathrm{Tf}_{2} \mathrm{~N}\right]$ on $\mathrm{Au}(111)$ at different temperatures and investigated the morphology and wetting behavior of the deposited films by atomic force microscopy. For multilayer coverages, we observe a drastically different growth behavior when comparing deposition at room temperature (RT) and deposition below $170 \mathrm{~K}$ followed by slow annealing to RT. Upon deposition at RT, we find the formation of 2-30 nm high and 50-500 $\mathrm{nm}$ wide metastable 3D droplets on top of a checkerboard-type wetting layer. These droplets spread out into stable $2 \mathrm{D}$ bilayers, on the time scale of hours and days. The same $2 \mathrm{D}$ bilayer structure is obtained after deposition below $170 \mathrm{~K}$ and slow annealing to RT. We present a statistical analysis on the

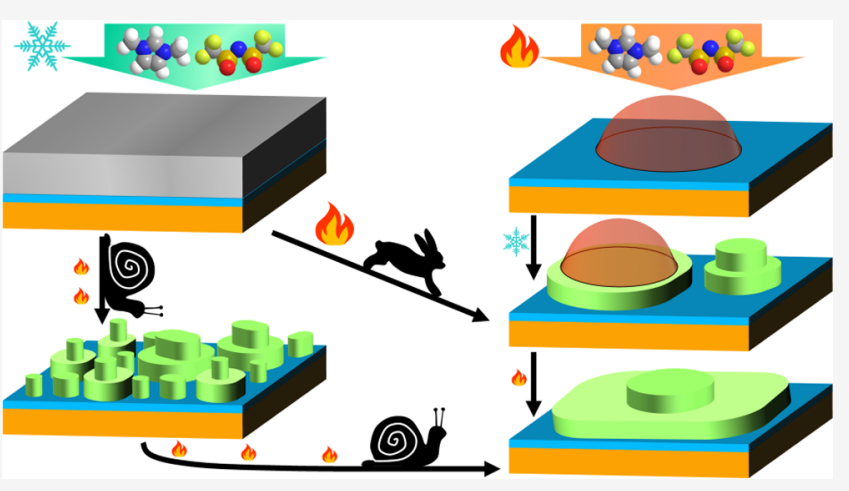
time-dependent changes of the shape and volume of the 3D droplets and the $2 \mathrm{D}$ bilayers. We attribute the stabilization of the $2 \mathrm{D}$ bilayers on the wetting layer and on already formed bilayers to the high degree of order in these layers. Notably, the transformation process from the $3 \mathrm{D}$ droplets to $2 \mathrm{D}$ bilayer islands is accelerated by tip effects and also X-ray radiation.

\section{INTRODUCTION}

Ionic liquids (IL) are a special class of liquids, which are interesting for a variety of applications, ranging from lubrication $^{1-5}$ to catalysis. $^{6-13}$ Their specific properties arise from the fact that they are molten salts, consisting of cations and anions, which can be varied over a wide range. Per definition, ILs are liquids below $100{ }^{\circ} \mathrm{C}$ and many of them even at room temperature (RT). Of particular interest are applications in catalysis, where ILs have recently led to two powerful concepts, both of which are already applied in largescale industrial processes. In both the supported ionic liquid phase $^{14}$ (SILP) concept and the solid catalyst with ionic liquid layer $^{13}$ (SCILL) concept, a high-surface-area solid substrate is covered with a thin IL film. In SILP, the IL film contains a dissolved metal complex, in SCILL the IL film modifies active sites at the support. It is evident that the formation of this film, in particular the question whether it wets the support material or not, is of utmost relevance for the catalytic performance in both concepts. ${ }^{15,16}$ Despite this importance, presently a molecular level understanding of the ongoing processes, which would allow for reliable predictions of the behavior for a particular combination of an ionic liquid and support, is missing.

The interaction of ILs with different supports has been studied in the past using various experimental techniques and conditions. ${ }^{16,17}$ For some systems, nearly perfect wetting of the substrate is found, yielding flat films of significant thickness, that is, the IL wets the surface; this behavior is also denoted as two-dimensional (2D) growth. In other cases, the IL forms three-dimensional (3D) islands, that is, the IL does not wet the surface. Here, one can differentiate between two cases: In the first, the IL forms a single wetting layer on the substrate, on top of which $3 \mathrm{D}$ islands (or droplets) grow. ${ }^{18}$ In the second, no such wetting layer is formed, and the $3 \mathrm{D}$ islands/droplets grow directly on the substrate. ${ }^{19}$

The experimental studies can be classified in two groups. In the first group, the films are prepared by e.g., spin- or dipcoating $^{20,21}$ under ambient conditions, that is, typically at room temperature and in air or in a controlled gas atmosphere. Common experimental techniques to study the growth behavior are contact angle measurements or ambient pressure atomic force microscopy. ${ }^{20-26}$ In the second group, ultrathin

Received: July 26, 2021

Published: September 10, 2021 
films of typically much lower thickness are prepared by physical vapor deposition (PVD) under ultraclean ultrahigh vacuum (UHV) conditions. As experimental methods, until recently only angle-resolved X-ray photoelectron spectroscopy (ARXPS) and UV-photoelectron spectroscopy (UPS) were applied. ${ }^{17,27-31}$ Only very recently, the first UHV-based atomic force microscopy (AFM) studies addressing IL growth have been published. ${ }^{32,33}$ Notably, scanning tunneling microscopy (STM) is not suited to study IL growth behavior, due to too strong tip effects, which occur for layers on top of the first wetting layer. ${ }^{33,34}$

Since in this study we will only deal with the growth behavior of ILs on well-defined single crystal surfaces, we will address the corresponding literature in more detail. A very good overview is provided in a recent review by Lexow et al. ${ }^{17}$ Upon IL deposition on clean metal and oxide surfaces, in all cases known to us, the formation of a wetting layer is observed. ${ }^{17,18,35-37}$ For the example of $\left[\mathrm{C}_{8} \mathrm{C}_{1} \mathrm{Im}\right]\left[\mathrm{Tf}_{2} \mathrm{~N}\right]$ on $\mathrm{Au}(111)$, this was initially deduced from angle-resolved XPS ${ }^{29}$ and later on confirmed by low-temperature STM. ${ }^{34}$ For most systems, this wetting layer displays a checkerboard-type structure with cations and anions adsorbed next to each other, both in direct contact with the surface. ${ }^{17}$ STM showed for several systems that the wetting layer can display a high degree of long-range order. Very recently it was demonstrated by STM and also by AFM that this order can even persist up to room temperature. ${ }^{32}$

The growth on top of the wetting layer depends on the substrate temperature and on the particular system. At room temperature, for some cases nearly perfect 2D layer-by-layer growth is observed up to 5-10 layers. ${ }^{29}$ For other systems, pronounced $3 \mathrm{D}$ islands form on the wetting layer on glass $\left(\mathrm{SiO}_{2}\right),{ }^{38} \mathrm{Au}(110),{ }^{36}$ mica, ${ }^{39}$ or $\mathrm{Ni}(111) .{ }^{40}$ In addition, also a behavior in between occurs, which was denoted as moderate 3D growth. ${ }^{17}$ These conclusions could be derived from ARXPS and UPS - for an overview see ref 17 . It was also noticed that specific modifications of the substrate, like surface alloying or carbon contaminations can lead to pronounced changes in the observed behavior. ${ }^{17,37,39}$ When adsorption is done at low temperature, typically a statistical growth (hit-and-stick) is observed. $^{33,41}$ Upon heating to RT, for some systems the formation of flat $2 \mathrm{D}$ layers is proposed, ${ }^{33,35}$ while for others dewetting, that is, the formation (ripening) of $3 \mathrm{D}$ islands occurs. $^{18}$

While the latter behavior is expected for systems, where the thermodynamics favors dewetting, there are some specific systems that show a seemingly opposite behavior. For these systems, at room temperature $3 \mathrm{D}$ islands form on top of the wetting layer, which transform into $2 \mathrm{D}$ layers over the time scale of minutes and hours. ${ }^{35,36}$ This behavior was exclusively deduced indirectly from the time-dependence of ARXPS ${ }^{35}$ or $\mathrm{UPS}^{36}$ signals. What is currently missing is real-space information about the growth and wetting behavior, providing information on the island size, shape, and height. While STM has proven to not be able to study IL systems at coverages beyond the wetting layer, very recently AFM has been demonstrated to allow for imaging distinct subsequent layers on top of the wetting layer, even with molecular resolution. For this reason, we herein perform AFM investigations of multilayer coverages of $\left[\mathrm{C}_{1} \mathrm{C}_{1} \operatorname{Im}\right]\left[\mathrm{Tf}_{2} \mathrm{~N}\right]$ on $\mathrm{Au}(111)$ formed upon adsorption at room temperature, with the aim to provide microscopic insights into the formation and thermal evolution of IL droplets in a highly controlled UHV environment. This knowledge can help to control or suppress the formation of droplets in IL thin films and is therefore potentially interesting for advanced SILP or SCILL systems. The IL was chosen because it showed time-dependent morphology changes after deposition on $\operatorname{Ag}(111)$ at $\mathrm{RT}^{35}$ This surface is very similar to $\mathrm{Au}(111)$ concerning the adsorption behavior of ILs. ${ }^{17}$

\section{METHODS}

We used a two-chamber variable temperature AFM/STM (VT-AFM-Q+-XA) from Scienta Omicron with a background pressure of $<1 \times 10^{-10}$ mbar. Ultrapure $\left[\mathrm{C}_{1} \mathrm{C}_{1} \mathrm{Im}\right]\left[\mathrm{Tf}_{2} \mathrm{~N}\right]$ (for synthesis see ref 27) was deposited following the same routine as described previously. ${ }^{33}$ Note that in the literature, $\left[\mathrm{C}_{1} \mathrm{C}_{1} \mathrm{Im}\right]^{+}$is also referred to as $[\mathrm{MMIm}]^{+42}$ and $\left[\mathrm{Tf}_{2} \mathrm{~N}\right]^{-}$as $\left[\mathrm{NTf}_{2}\right]^{-43}$ or $[\mathrm{TFSA}]^{-3}$. The $\mathrm{Au}(111)$ crystal was purchased from $\mathrm{MaTecK}$ and cleaned by repeated $\mathrm{Ar}^{+}$sputtering and annealing until the terraces were a few hundred nanometres broad and appeared clean in AFM. In a previous publication, we showed that the $\mathrm{Au}(111)$ herringbone reconstruction is not lifted by $\left[\mathrm{C}_{1} \mathrm{C}_{1} \mathrm{Im}\right]\left[\mathrm{Tf}_{2} \mathrm{~N}\right]$. $^{32}$ The deposition was performed using a homebuilt effusion cell for $\mathrm{ILs}^{44}$ operated at a temperature around $380 \mathrm{~K}$. IL deposition was done in the preparation chamber with the substrate at room temperature, $250 \mathrm{~K}$, or during cooling with liquid nitrogen at temperatures below $170 \mathrm{~K}$. After deposition, the sample was transferred to the precooled AFM/STM sample stage in the analysis chamber at $110 \mathrm{~K}$ (transfer time: $4-8 \mathrm{~min}$, including the time to cool down to $110 \mathrm{~K}$ of $1-2 \mathrm{~min}$ ). The deposited amount was precisely determined using a calibrated QCM that was positioned besides the crystal during deposition. ${ }^{33}$ The deposited amounts are given in WLE, that is, multiples of the dose required to form one complete densely packed wetting layer with a coverage of $1 \mathrm{WL}$. Please note that in the literature coverages are often given in ML, which for ILs has been defined as the surface fully covered with pairs of cations and anions on top of each other. Therefore, for systems where the wetting layer has a checkerboard-like structure (as is the case here), with cations and anions next to each other in contact with the surface, $1 \mathrm{WL}$ equals $0.5 \mathrm{ML}$. The frequency shift $\Delta f$ of the noncontact AFM measurements was mostly $-300 \mathrm{~Hz}$ versus resonance frequency of the cantilever, usually around $300 \mathrm{kHz}$. A table with detailed information on the preparation conditions for all shown images is given in the SI.

Data evaluation and image processing was done using $\mathrm{WSxM}^{45}$ and involved precise background flattening and sparingly used filtering for noise reduction in presented images. Lateral droplet sizes were determined from the $x$ and $y$ dimensions, omitting noise as good as possible. Vertical sizes were determined from the highest height diagram in the fastscan direction that was free of noise. Volumes were calculated for each individual droplet by assuming an ellipsoidal shape. Covered surface areas of the bilayers were determined by "flooding" the images at a threshold of $50 \%$ of the height level of the respective layer, relative to the lower layer.

\section{RESULTS}

We deposited defined amounts of $\left[\mathrm{C}_{1} \mathrm{C}_{1} \mathrm{Im}\right]\left[\mathrm{Tf}_{2} \mathrm{~N}\right]$ onto $\mathrm{Au}(111)$ via PVD using a custom-made IL evaporator, ${ }^{44}$ which provides a stable IL flux over a long time. The IL flux was monitored by a calibrated quartz crystal microbalance (QCM) positioned next to the sample during the deposition. From the QCM signal, we can thus precisely determine the IL coverage 


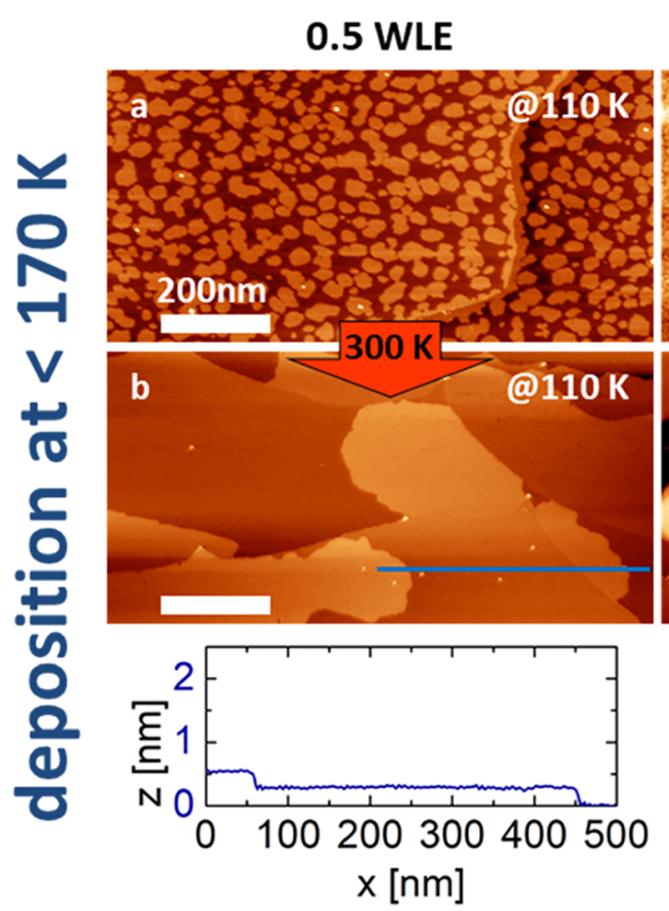

0.5 WLE
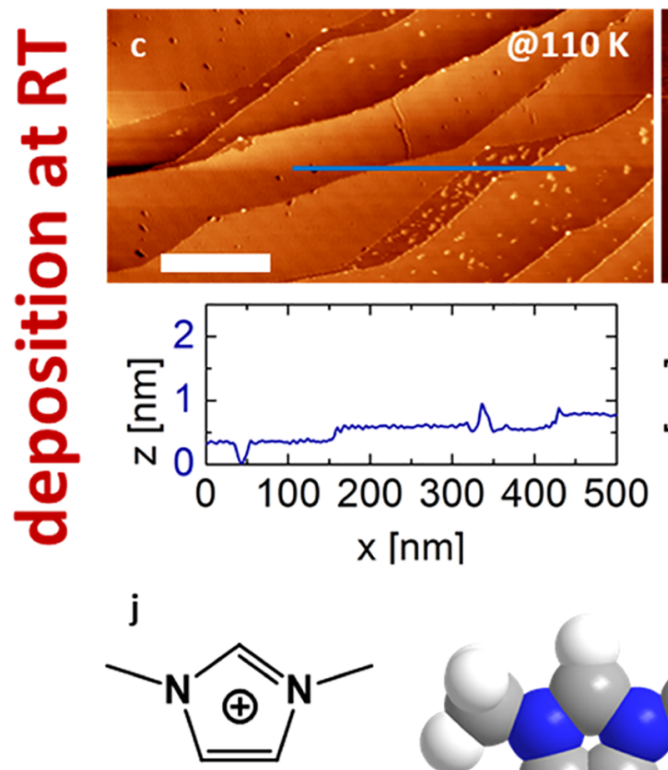

$\left[\mathrm{C}_{1} \mathrm{C}_{1} \mathrm{Im}\right]^{+}$
1.9 WLE
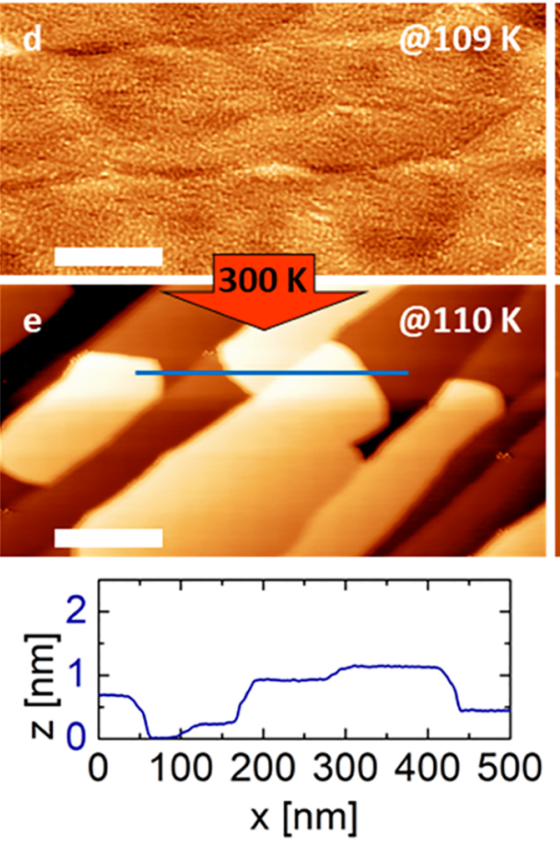

2.2 WLE
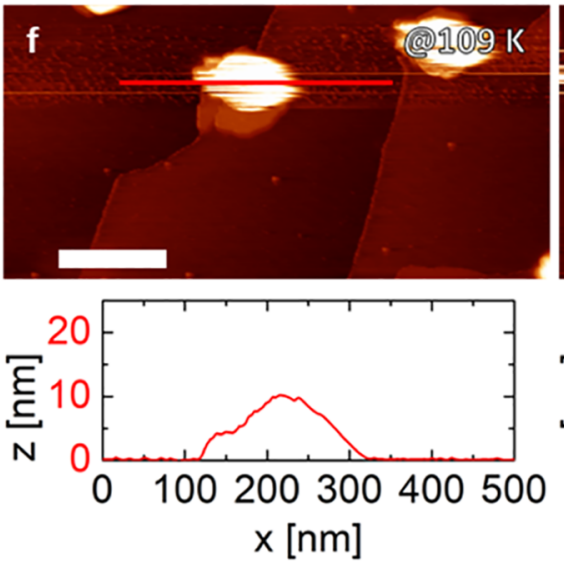

3.9 WLE
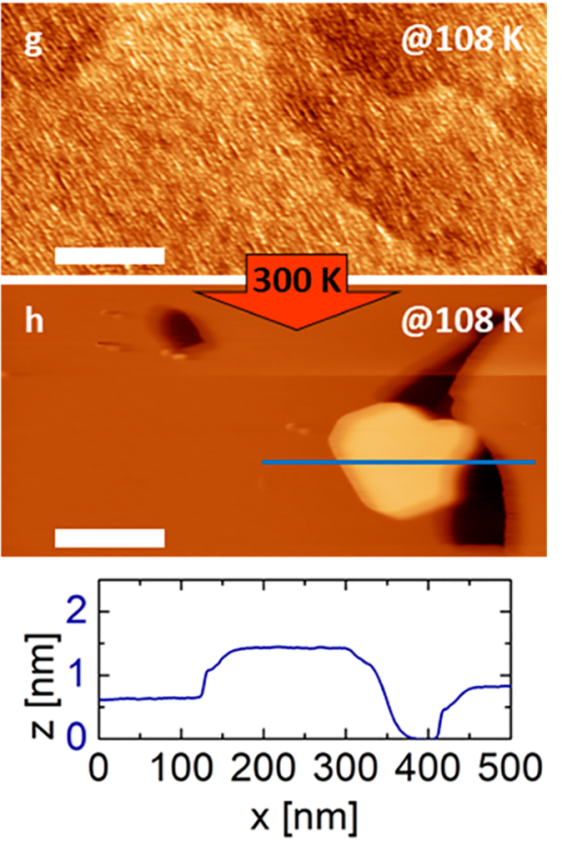

4.2 WLE
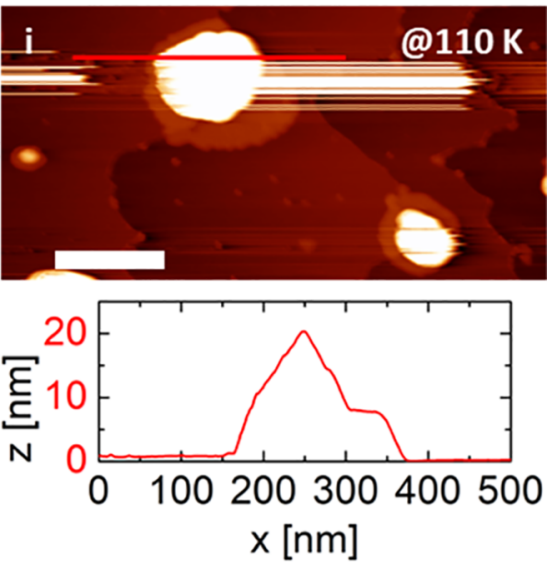
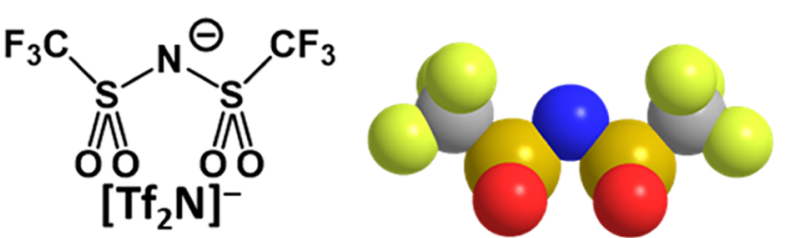

Figure 1. AFM images of $\left[\mathrm{C}_{1} \mathrm{C}_{1} \mathrm{Im}\right]\left[\mathrm{Tf}_{2} \mathrm{~N}\right]$ on $\mathrm{Au}(111)$, all measured at $110 \mathrm{~K}$, for deposited amounts of $0.5 \mathrm{WLE}$ (left), $2 \mathrm{WLE}$ (center), and 4 WLE (right). (a, d, g) display the images after deposition at temperatures below $170 \mathrm{~K}$ and (b, e, h) after slow annealing (over days) of these layers to $300 \mathrm{~K}$; below the latter, representative line scans are shown, the positions of which are indicated in the images above by blue horizontal lines. (c, f, i) display the images after deposition at RT; representative line scans are shown below as blue or red horizontal lines-note the different height scales. The chemical structure and space-filling models of $\left[\mathrm{C}_{1} \mathrm{C}_{1} \mathrm{Im}\right]\left[\mathrm{Tf} \mathrm{f}_{2} \mathrm{~N}\right]$ are shown in $(\mathrm{j})$. Details about the preparation and $\mathrm{AFM}$ parameters are given in the SI.

(under the reasonable assumption that the IL sticking coefficient does not depend on IL coverage), as described previously. ${ }^{33} \mathrm{IL}$ deposition was done with the substrate either held at room temperature, at $\sim 250 \mathrm{~K}$, or at temperatures below $170 \mathrm{~K}$ (below this temperature, no changes of the surface morphology with time are observed). AFM images were measured at 110 or $250 \mathrm{~K}$. At $250 \mathrm{~K}$, stable AFM imaging in the multilayer range is still possible. Above $270 \mathrm{~K}$, the tip picks up IL from the surface and redeposits it in an uncontrolled way, as reported previously. ${ }^{33}$

Figure 1 shows $\mathrm{AFM}$ images for doses of $0.5, \sim 2$, and $\sim 4$ WLE of $\left[\mathrm{C}_{1} \mathrm{C}_{1} \mathrm{Im}\right]\left[\mathrm{Tf}_{2} \mathrm{~N}\right]$ on $\mathrm{Au}(111)$. The IL doses are given in wetting layer equivalents (WLE), where $1 \mathrm{WLE}$ is the dose required for the formation of a complete densely packed wetting layer (WL) on $\mathrm{Au}(111)$. At the top (Figure 1a,d,g), we show AFM images obtained after deposition at a sample 
1
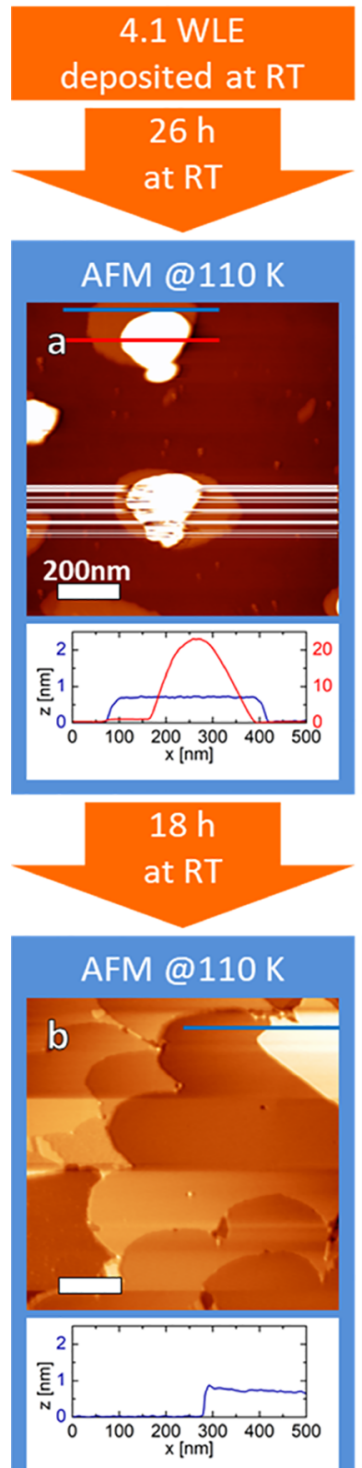

2
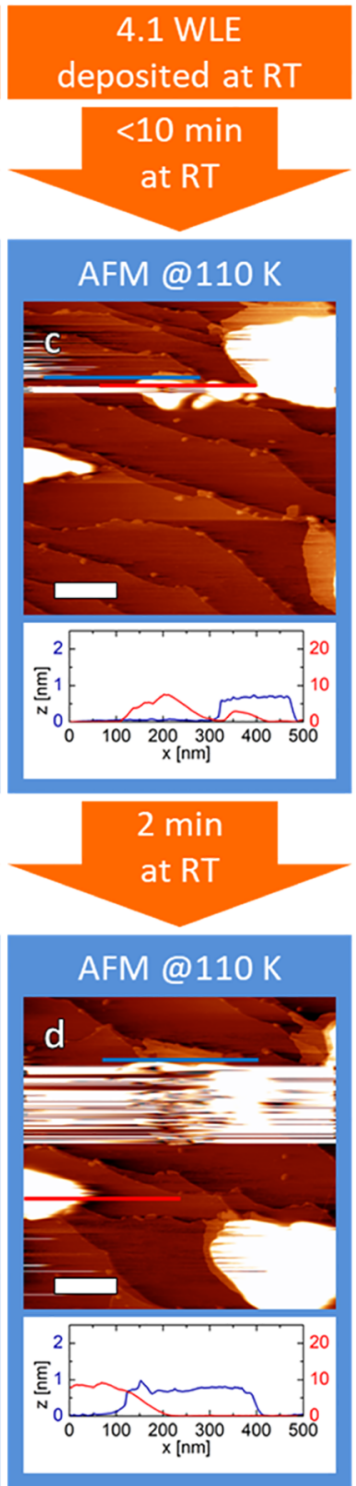

3
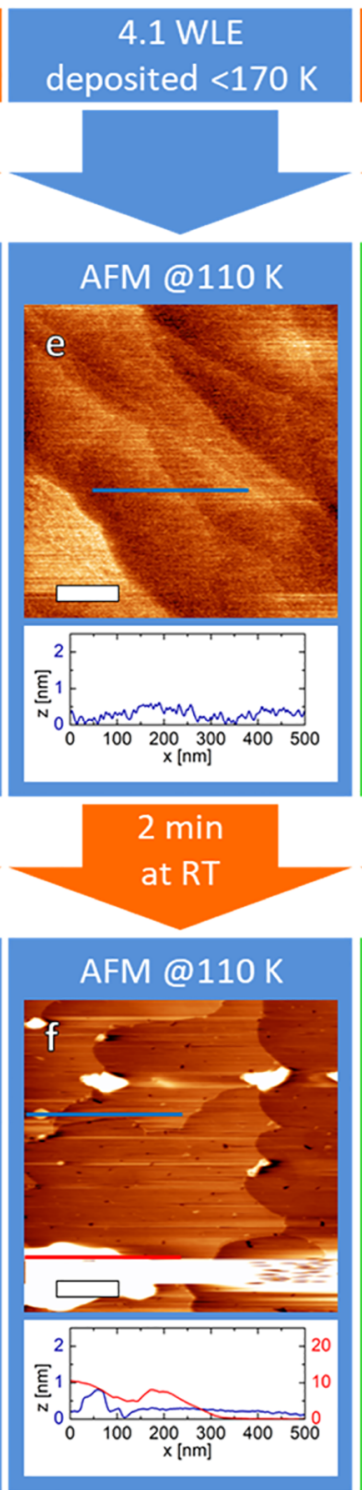

4

4.1 WLE

deposited at RT
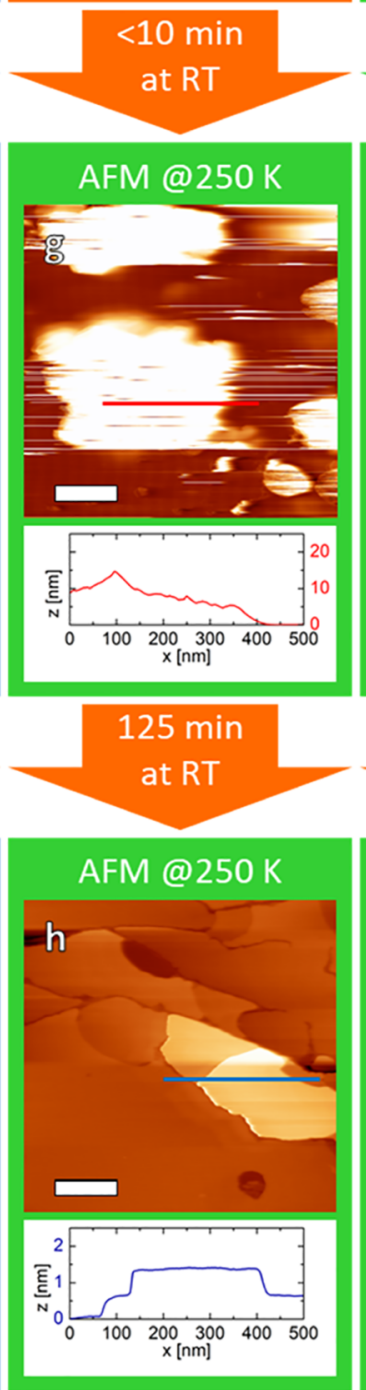

5
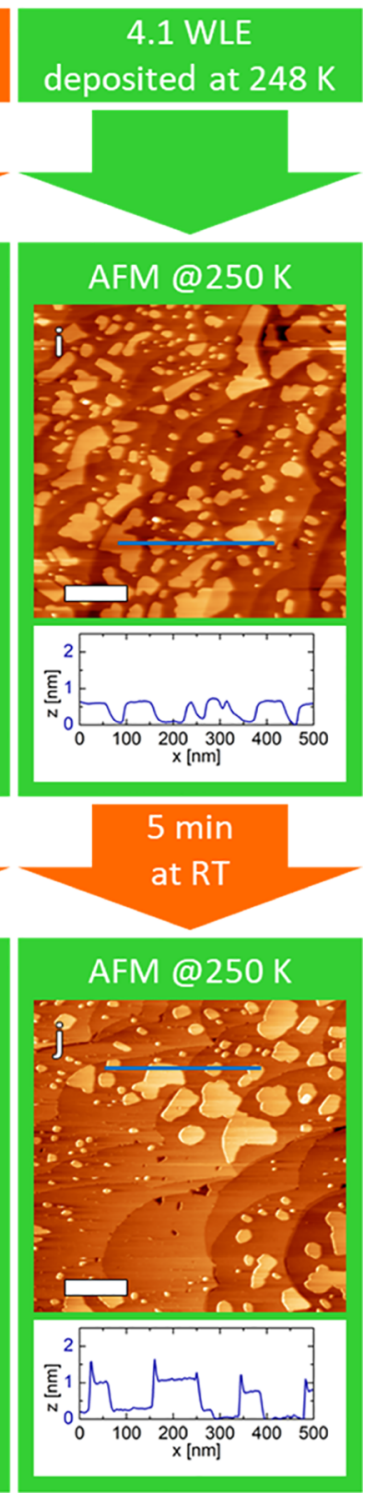

Figure 2. AFM images of $4.1 \mathrm{WLE}\left[\mathrm{C}_{1} \mathrm{C}_{1} \mathrm{Im}\right]\left[\mathrm{Tf} \mathrm{f}_{2} \mathrm{~N}\right]$ on $\mathrm{Au}(111)$, measured at $110 \mathrm{~K}$ (blue frames) or at $250 \mathrm{~K}$ (green frames). Below each image representative line scans are shown, the positions of which are indicated in the images above by blue and/or red horizontal lines (note the different scales). Experiment 1: deposition at RT followed by $26 \mathrm{~h}$ at RT, AFM at $110 \mathrm{~K} \mathrm{(a)} \mathrm{and} \mathrm{subsequent} \mathrm{annealing} \mathrm{at} \mathrm{RT} \mathrm{for} 18 \mathrm{~h}$ and AFM at $110 \mathrm{~K}$ (b). Experiment 2: deposition at RT followed by $<10 \mathrm{~min}$ at RT, AFM at $110 \mathrm{~K}$ (c) and subsequent annealing at RT for $2 \mathrm{~min}$ and AFM at $110 \mathrm{~K}$ (d). Experiment 3: deposition at $<170 \mathrm{~K}$, followed by AFM at $110 \mathrm{~K}$ (e) and subsequent annealing at RT for 2 min and AFM at $110 \mathrm{~K}$ (f). Experiment 4: deposition at RT followed by $<10 \mathrm{~min}$ at RT, AFM at $250 \mathrm{~K}(\mathrm{~g})$ and annealing at RT for $125 \mathrm{~min}$ and AFM at $250 \mathrm{~K}$ (h). Experiment 5: deposition at $248 \mathrm{~K}$, followed by AFM at $250 \mathrm{~K}$ (i) and annealing at RT for $5 \mathrm{~min}$ and AFM at $250 \mathrm{~K}$ (j). Details about the preparation and AFM parameters are given in Table S1 in the SI.

temperature below $170 \mathrm{~K}$; the AFM measurements were performed at $110 \mathrm{~K}$. In the row below, AFM images are shown after slow annealing of the layers of the top row to $300 \mathrm{~K}$ (Figure 1b,e,h), again measured at $110 \mathrm{~K}$; slow annealing means that the final temperature is reached after several days, while taking additional AFM images at intermediate temperatures (not shown). The bottom row shows AFM images of samples with doses nearly identical to those in the top row but with the deposition performed with the substrate at RT (Figure 1c,f,i). After deposition, the samples were immediately cooled to $110 \mathrm{~K}$ (within $4-8 \mathrm{~min}$, to freeze in the film morphology) and then measured at $110 \mathrm{~K}$. The corresponding line scans displaying the island heights are given below.
For the dose of 0.5 WLE (left column), that is, for a coverage of $0.5 \mathrm{WL}$, we observe a large number of small $2 \mathrm{D}$ islands for deposition at low temperature; see Figure 1a. Upon slow annealing to room temperature, very large $2 \mathrm{D}$ islands form (Figure $1 \mathrm{~b}$ ). This appearance is very similar to that of the IL layer directly deposited at RT (Figure 1c), indicating that in the sub-WL range the same morphology is achieved by adsorption at low temperature plus annealing to RT and by deposition at RT.

For doses exceeding 1 WLE (and thus a coverage $>1 \mathrm{WL}$ ), the adsorption behavior strongly differs for the two deposition temperatures and becomes even more different after annealing to RT. For deposition at low temperature, we observe a 

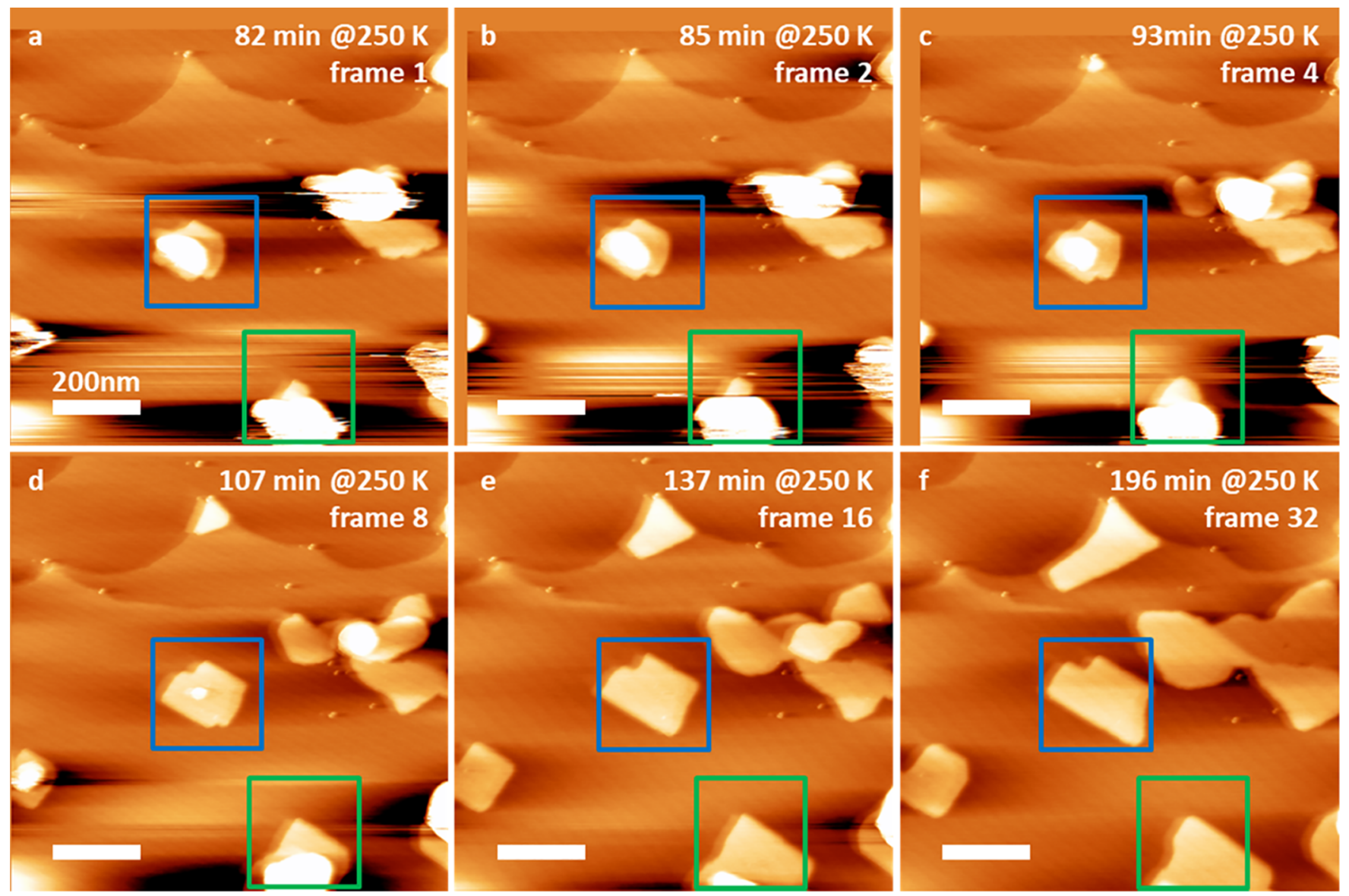

Figure 3. AFM images of $2.2 \mathrm{WLE}\left[\mathrm{C}_{1} \mathrm{C}_{1} \mathrm{Im}\right]\left[\mathrm{Tf}_{2} \mathrm{~N}\right]$ deposited onto $\mathrm{Au}(111)$ at room temperature, cooled to $110 \mathrm{~K}$, and then measured at $250 \mathrm{~K}$ repeatedly over a time span of $114 \mathrm{~min}$; the images are part of an AFM video (over $174 \mathrm{~min}$ ), which started $82 \mathrm{~min}(1.4 \mathrm{~h}$ ) after the annealing has been initialized. Notably, always the identical area of the surface was scanned, thus allowing for the analysis of the time evolution of individual droplets. Two are indicated by green and blue squares. Evidently, with time the 3D droplets are converted to $2 \mathrm{D}$ bilayer islands. The full AFM video is provided as Video V1 in the SI, along with the details about the preparation and AFM parameters in Table S1.

homogeneously covered surface consisting of many very small features $(5-10 \mathrm{~nm})$ with a height distribution around $0.5 \mathrm{~nm}$ (see Figure 1d,g). Upon slow annealing to RT, the system undergoes a transition to a layered 2D structure (Figure le, h; note that the smaller steps with $\sim 0.2 \mathrm{~nm}$ height are due to steps of the $\mathrm{Au}(111)$ substrate); molecularly resolved highresolution images reveal a crystalline order of this $2 \mathrm{D}$ structure (see Figure S1 in the Supporting Information (SI)). ${ }^{33}$ Large islands are formed on top of a closed wetting layer; the height of these islands, as deduced from line scans, is $\sim 0.71 \mathrm{~nm}$ (see line scans in Figure 1e,h). This is twice the height of the wetting layer of $\sim 0.34 \mathrm{~nm}$, in agreement with ref 33 , and confirms the growth of bilayers on top of the wetting layer under these conditions. The situation changes drastically, when deposition is performed directly at RT (Figure 1f,i), where very large droplets with heights around $2-30 \mathrm{~nm}$ and diameters around 50-500 nm form (see line scans in Figure 1f,i; note the different height scales). The $2 \mathrm{D}$ bilayer islands that are found for the cold-prepared and slowly annealed layers (Figure 1e,h) are absent, except for small terrace-like features around some of the droplets. Notably, the remaining flat area between the droplets is not the clean $\mathrm{Au}(111)$ surface but the substrate entirely covered with the wetting layer, as concluded from its molecular resolved structure (see Figure S2 in the SI).

To obtain additional information on the growth behavior and on the transition of the $3 \mathrm{D}$ droplets to the $2 \mathrm{D}$ bilayers on
$\mathrm{Au}(111)$, we performed a series of five experiments, with different deposition temperatures, annealing times, and imaging temperatures. In each experiment, we deposited the same nominal amount of 4.1 WLE onto a freshly cleaned sample, and after each preparation step we collected around 10 AFM images. For each step, a representative image is shown in Figure 2.

In experiment 1 , we deposited the IL at RT and left the sample at RT for $26 \mathrm{~h}$. The AFM image in Figure 2a, measured after cooling to $110 \mathrm{~K}$ (within $1-2 \mathrm{~min}$ ), is very similar to that in Figure 1i. It shows a few large 3D droplets of up to $25 \mathrm{~nm}$ in height, some of which are surrounded by $2 \mathrm{D}$ bilayer islands of $0.7 \mathrm{~nm}$ height (see red and blue line scans below the AFM image, respectively). As the next step, we heated the sample back to RT (within 1-2 $\mathrm{min}$ ) and retained it at this temperature for $18 \mathrm{~h}$. The AFM image after cooling back to $110 \mathrm{~K}$ is shown in Figure $2 \mathrm{~b}$. Interestingly, the 3D droplets have disappeared and we find the surface covered with $2 \mathrm{D}$ bilayers. Obviously, during the time the sample spent at temperatures between RT and $110 \mathrm{~K}$, nuclei of $2 \mathrm{D}$ bilayers have formed, so that these islands continued to grow at RT.

To find out when the transition of the $3 \mathrm{D}$ droplets to $2 \mathrm{D}$ bilayers happens, we performed experiment 2 . In contrast to experiment 1 , the time at RT directly after deposition was decreased to only a few $(<10)$ minutes, before cooling to 110 K. In Figure 2c, we still find droplets as before, along with a 

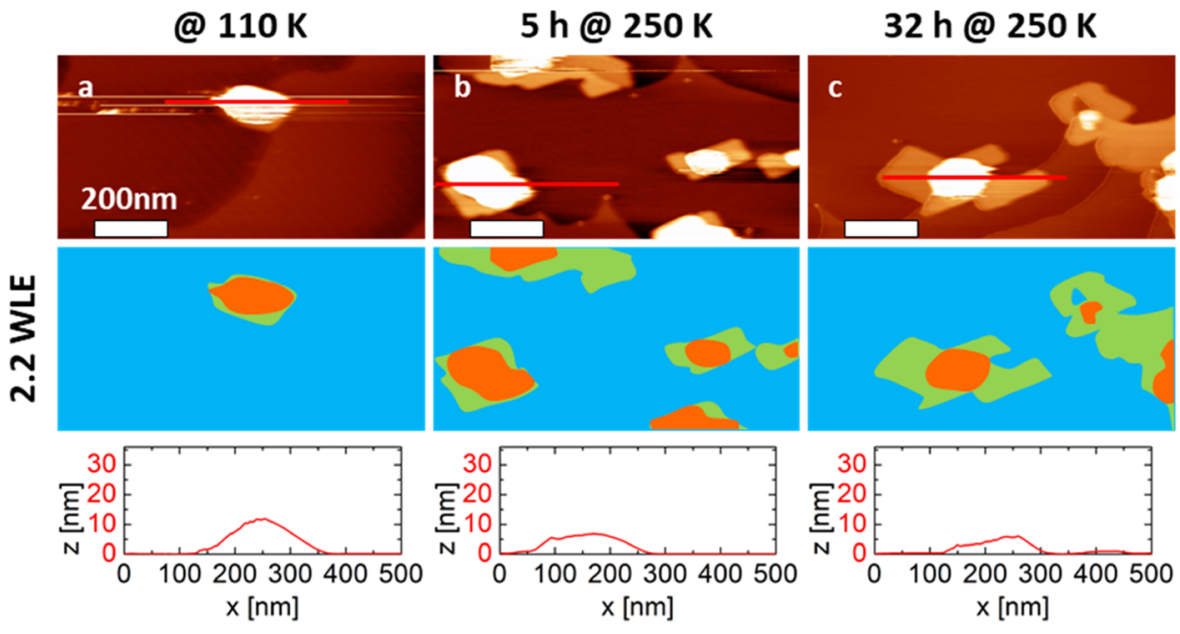

$100 \mathrm{~h} @ 250 \mathrm{~K}$
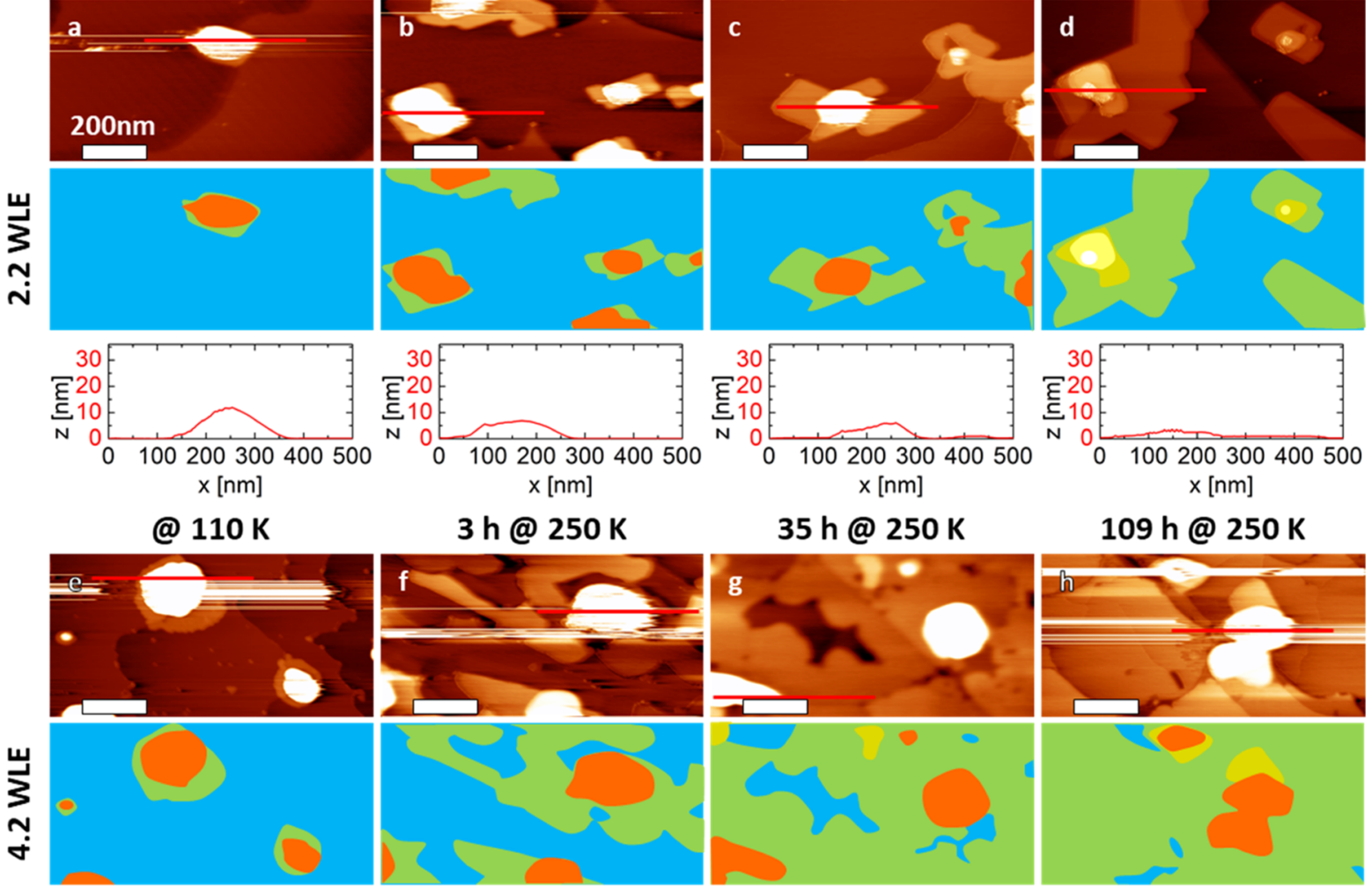

3 h @ 250 K

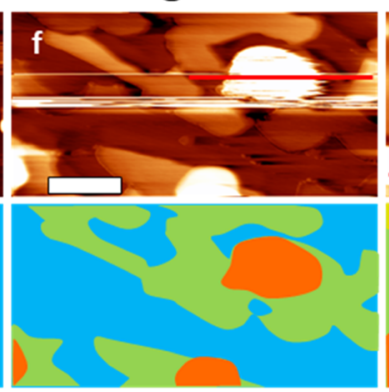

35 h @ 250 K
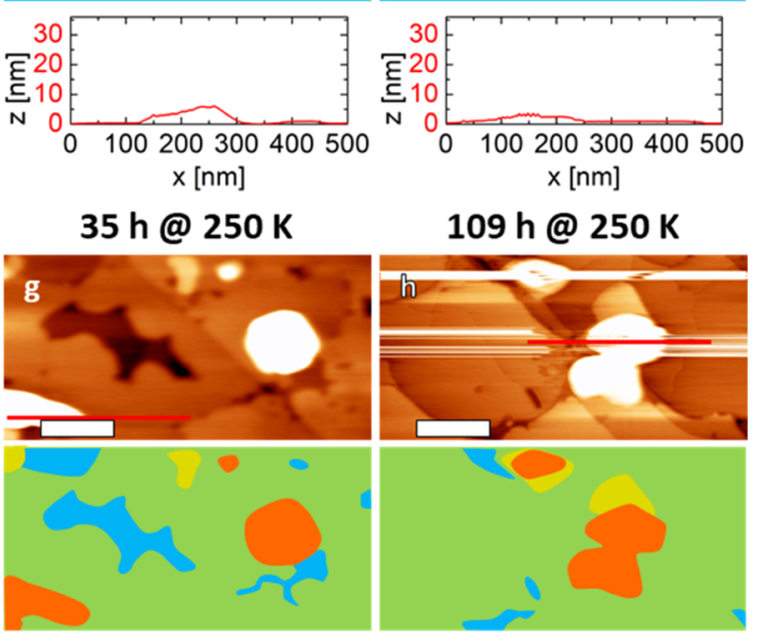

$109 \mathrm{~h} @ 250 \mathrm{~K}$
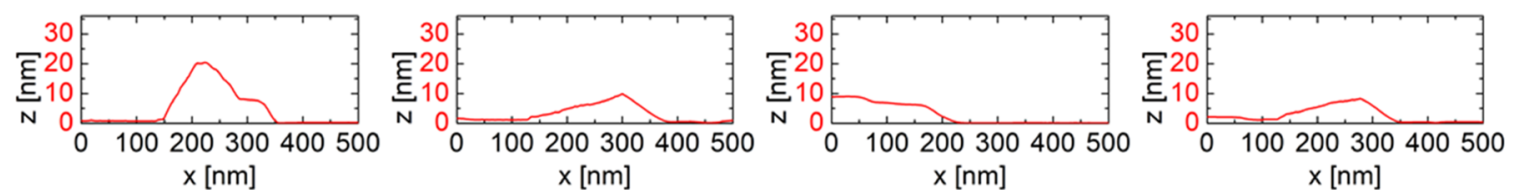

@ $110 \mathrm{~K}$

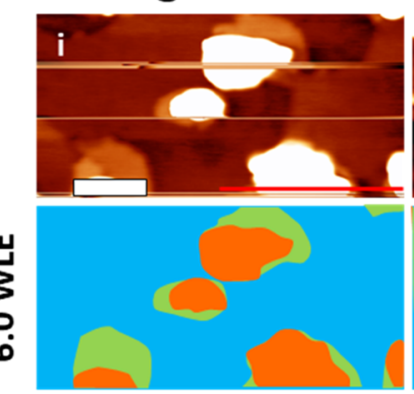

$3 \mathrm{~h} @ 250$ K

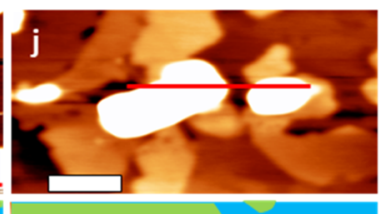

34 h @ 250 K
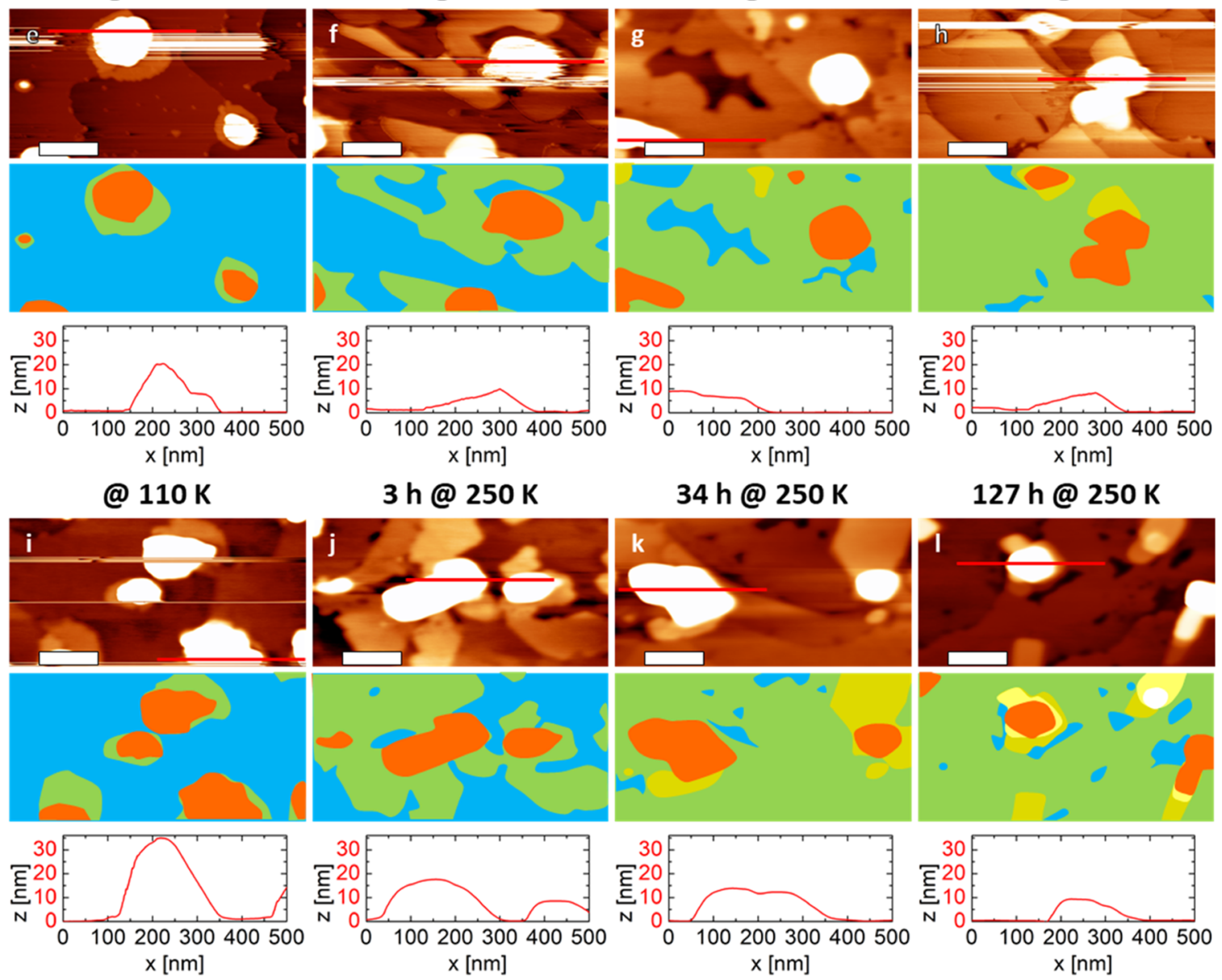

127 h @ 250 K
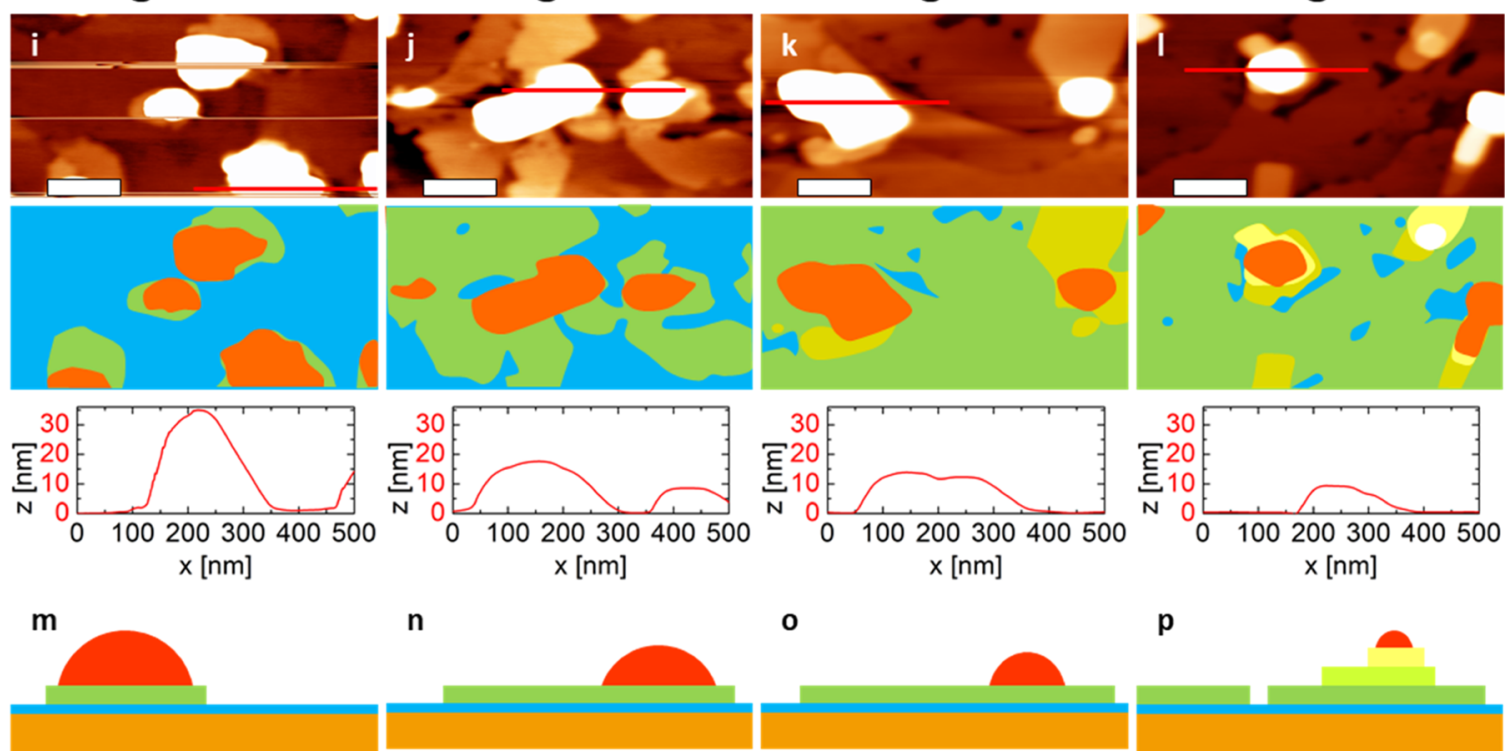

Figure 4. AFM images of 2.2 WLE (top panel a-d), 4.2 WLE (middle, e-h), and 6.0 WLE (bottom, i-l) [ $\left.\mathrm{C}_{1} \mathrm{C}_{1} \operatorname{Im}\right]\left[\mathrm{Tf}_{2} \mathrm{~N}\right]$ deposited onto $\mathrm{Au}(111)$ at RT, measured at $110 \mathrm{~K}$ (left column), and then at $250 \mathrm{~K}$, over a period of 100-127 h. In each panel, the AFM image, a color-coded flooding of the image (to identify the wetting layer, bilayers, and droplets), and a representative line scan are arranged above each other. The sample remained at $250 \mathrm{~K}$ through the measurement series, and for each image a new spot on the surface was scanned to minimize tip-induced effects. Schematic sketches of the surface morphology are shown in $(m-p)$. Details about the preparation and AFM parameters are given in the SI in Table S1.

few $2 \mathrm{D}$ bilayer regions around them. Obviously, the time at RT directly after deposition at RT does not have a major effect on the growth behavior. However, the annealing time at RT after measuring the AFM images at $110 \mathrm{~K}$ strongly influences the 
(a) droplet number

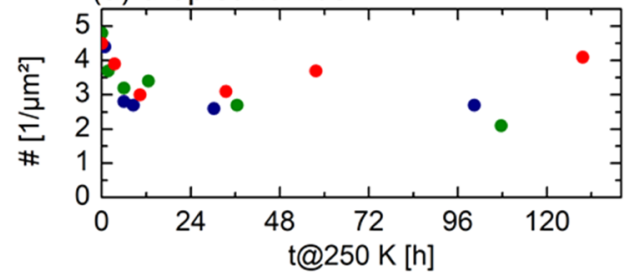

(b) droplet diameter

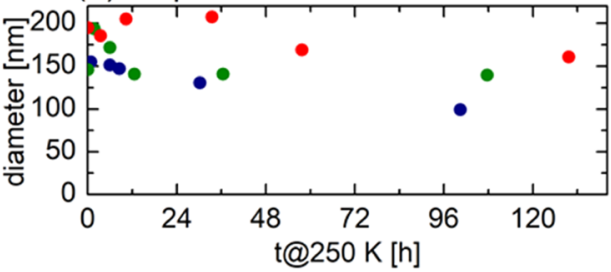

(c) droplet height

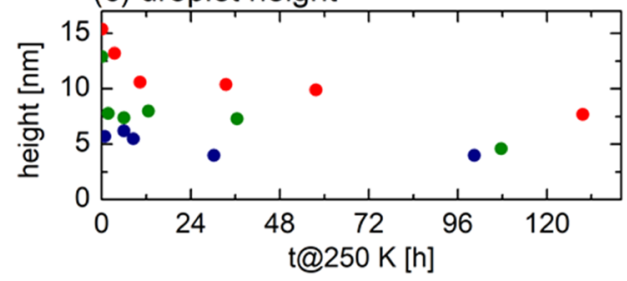

(d) droplet volume

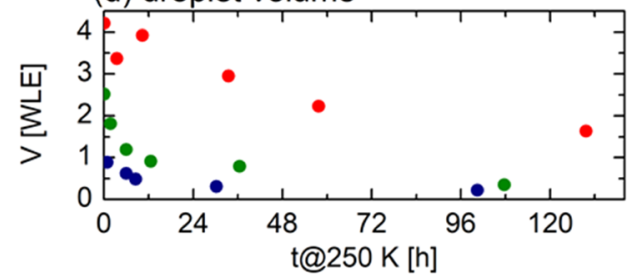

(e) BL volume
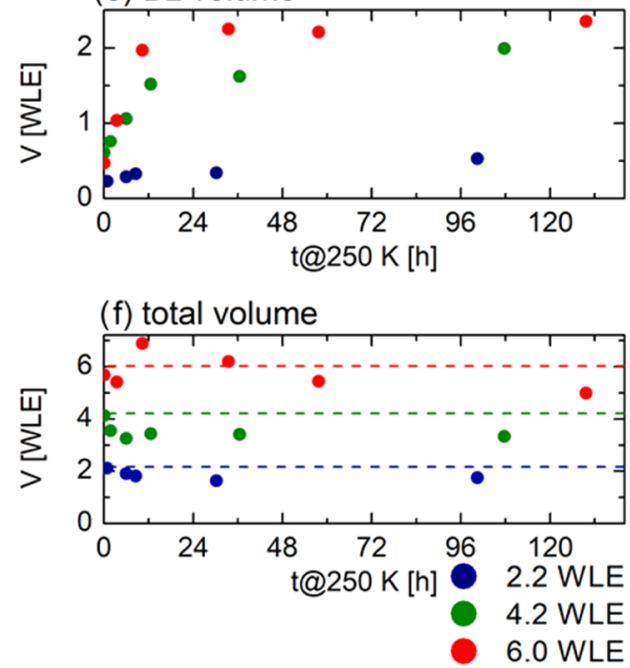

Figure 5. Statistical analysis of the time evolution of AFM images of $2.2 \mathrm{WLE}$ (blue), 4.2 WLE (green), and 6.0 WLE (red) [ $\left.\mathrm{C}_{1} \mathrm{C}_{1} \mathrm{Im}\right]\left[\mathrm{Tf} \mathrm{f}_{2} \mathrm{~N}\right]$, deposited onto $\mathrm{Au}(111)$ at $\mathrm{RT}$, measured at $110 \mathrm{~K}$, and then at $250 \mathrm{~K}$, over a period of 100-127 h; the data stem from the same experimental series as the AFM images shown in Figure 4. For each data point, 7-34 images (containing 21-90 droplets) were analyzed. (a) Average number of droplets, (b) average droplet diameter (average of the length and width of the slightly elliptical shape; see text), (c) average droplet height, (d) average droplet volume, (e) average bilayer volume, and (f) average total volume; the deposited amount is indicated by dashed lines, respectively.

results: While in experiment 1 we found predominantly $2 \mathrm{D}$ bilayers after $18 \mathrm{~h}$ (Figure $2 \mathrm{~b}$ ), annealing for only $2 \mathrm{~min}$ at RT leaves the morphology mostly unaffected, as is evident from Figure $2 \mathrm{~d}$, where the $3 \mathrm{D}$ droplets still dominate the appearance. This behavior indicates that the transition from $3 \mathrm{D}$ droplets to $2 \mathrm{D}$ bilayers is a slow process requiring a certain annealing time at RT (on the order of hours) but only happens if the sample has been cooled to low temperature before this step.

To obtain further insight, we performed an additional experiment 3, where we deposited the IL at low temperatures (below $170 \mathrm{~K}$ during cooling). The corresponding AFM image in Figure $2 \mathrm{e}$ shows a homogeneously covered surface consisting of many very small structures (similar to Figure $1 \mathrm{~g}$ ), which we attribute to a homogeneously thick disordered layer due to hit-and-stick adsorption of ion pairs. Upon short (2 min) annealing to RT, the surface morphology changes completely and 3D droplets are observed along with $2 \mathrm{D}$ bilayer regions; see Figure 2f. This observation contrasts the situation obtained after slowly (over days) annealing a low temperaturedeposited layer to RT, where only $2 \mathrm{D}$ bilayers are seen, $\mathrm{cf}$. Figure $1 \mathrm{~h}$. We thus conclude that upon fast annealing of a lowtemperature-deposited disordered IL layer to RT, the IL agglomerates to $3 \mathrm{D}$ droplets. When this annealing process is performed over a long time, 2D bilayers are formed.

In experiment 4, the IL was deposited at RT and cooled to $250 \mathrm{~K}$ within less than $10 \mathrm{~min}$ after preparation. We also measured the AFM images at this temperature, to avoid cooling to $110 \mathrm{~K}$. Figure $2 \mathrm{~g}$ again shows $3 \mathrm{D}$ droplets along with some $2 \mathrm{D}$ bilayer regions. Upon annealing at RT for 125 min and cooling back to $250 \mathrm{~K}$, the $3 \mathrm{D}$ droplets completely convert to $2 \mathrm{D}$ bilayers, as is evident from Figure $2 \mathrm{~h}$.

For experiment 5, we changed the deposition temperature to $248 \mathrm{~K}$. The AFM images in Figure 2i, which were measured at $250 \mathrm{~K}$ directly after deposition, show exclusively $2 \mathrm{D}$ bilayers, with no sign of $3 \mathrm{D}$ droplets. Obviously, upon deposition at 250 $\mathrm{K}$, the $\mathrm{IL}$ does not agglomerate to $3 \mathrm{D}$ droplets and the $2 \mathrm{D}$ bilayers are formed directly. Annealing at RT for 5 min does not change the situation, as is evident from Figure $2 \mathrm{j}$, which shows that no $3 \mathrm{D}$ droplets are formed once $2 \mathrm{D}$ bilayers have been formed.

In the experimental series shown in Figures 1 and 2, we observed a very complex adsorption and growth behavior. To obtain further insight, we followed the time evolution of the transformation of 3D droplets to 2D bilayers in situ over an extended time period with an AFM video. For this experiment, we deposited 2.2 WLE at RT and immediately cooled the sample to $110 \mathrm{~K}$. Thereafter, we heated the sample to $250 \mathrm{~K}$ and began the AFM measurements. After 82 min, we started a video of a selected surface area. Single frames of this video are shown in Figure 3 for a time span of $114 \mathrm{~min}$, and the full video $(174 \mathrm{~min})$ is presented as Video V1 in the SI. The initial image in Figure 3a contains a few large 3D droplets (two are highlighted with squares) on top of the wetting layer, with only small 2D-bilayer regions connected to the perimeter of the droplet. With time, the droplet decreases in size and simultaneously a $2 \mathrm{D}$ bilayer emerges from the perimeter of the droplet and grows outwards. Eventually all droplets disappear, and the surface is only covered with bilayer islands (Figure 3f); this situation equals the appearance, which is 
observed after deposition at low temperature followed by slow annealing to $300 \mathrm{~K}$ (cf. Figure 1e). At intermediate times (Figure 3c,d), step-pyramid-like structures displaying several levels, with heights equaling the bilayer height of $\sim 0.71 \mathrm{~nm}$, as found in a previous publication, are observed. ${ }^{33}$ Eventually these also tend to spread out into the lowest bilayer, if given enough time.

After performing the time-series experiment shown in Figure 3 , we moved to a different spot on the sample and checked whether the same transition from the droplet to the $2 \mathrm{D}$ layer had occurred. Surprisingly, we observed that the image at the new spot looked quite different, that is, it still showed pronounced droplets. We thus have to conclude that we have pronounced tip effects, namely, that the tip accelerates the transition from droplets to the $2 \mathrm{D}$ structure.

To avoid the influence of tip effects, we thus performed three series of isothermal measurements at $250 \mathrm{~K}$, at three different IL doses, 2.2, 4.2, and 6.0 WLE. However, this time each image was taken at a new, previously not scanned region to avoid tip-induced effects; notably, this has the disadvantage that one cannot follow the evolution of the same droplets on the surface. During IL deposition, the substrate was at RT, followed by an immediate transfer (within 4-8 $\mathrm{min}$ ) to the precooled measurement stage at $110 \mathrm{~K}$. The sample was then heated to $250 \mathrm{~K}$ and held at this temperature for the entire series of AFM measurements (up to 5 days). Figure 4 shows representative AFM images from the three series at the beginning, after annealing times of 3-5, 32-35, and 100$127 \mathrm{~h}$. Below each image, a color-coded image indicating the respective layers or droplets is shown, along with a line scan of the highest droplet in the respective image. We observe that for all doses, droplets with similar perimeter have been formed. Upon annealing, these droplets decrease in size and a bilayer spreads around the droplets. The height of all bilayers is $\sim 0.71$ $\mathrm{nm}$, which equals the height of the bilayers described in a previous publication. ${ }^{33}$ At longer times, the droplets lose their ill-defined shape and step-pyramid-like structures are seen. Eventually, the lower bilayers close (until they fully cover the surface), and the higher layers vanish. Overall, the observed behavior is identical to that in Figure 3. The only difference is that it occurs much faster when always the identical surface area is scanned. We thus conclude that the transformation from the droplets to the $2 \mathrm{D}$ layers occurs independent of the AFM tip. This observation is in line with ARXPS and UPS experiments for similar systems, which also suggested the initial formation of $3 \mathrm{D}$ islands, which convert to $2 \mathrm{D}$ islands with time. $^{35}$

For all three coverages, we performed a statistical analysis of the droplets by determining their footprint and height and of the area occupied by a 2D-bilayer (including the footprint of the droplet). The footprint of the droplets is roughly circular, with a slight tendency toward an elliptical shape, with the longer axis along the fast scanning direction (horizontal); this effect is likely due to an influence of the tip. The droplet volume was determined from the average diameter and height of each individual droplet, yielding a broad distribution (see Figure S3 in the SI). For the three depositions, at each time step between 7 and 34 images were analyzed, which contained on average between 2 and 5 droplets (thus altogether in each case 21-90 droplets were analyzed).

Figure 5 shows the statistical evaluation of the droplets (average number and average diameters, heights, and volumes) and bilayers (average volume) directly after deposition $(t=0$ $\min$ ) and their evolution with time (up to $127 \mathrm{~h}$ ) at $250 \mathrm{~K}$. Notably, the initial average number of droplets directly after deposition (that is, $t=0 \mathrm{~h}$ ) increases only slightly with increasing dose. While the initial diameters (average of extensions along and perpendicular to the scanning direction) of the droplets increase only from $\sim 150 \mathrm{~nm}$ at 2.2 WLE to $\sim 200 \mathrm{~nm}$ at $6.0 \mathrm{WLE}$, their average heights increase strongly, from $\sim 6 \mathrm{~nm}$ at 2.2 WLE to $\sim 15 \mathrm{~nm}$ at 6.0 WLE. This means that upon increasing the deposited amount, the initially formed islands grow mostly in height. For all coverages, directly after deposition nearly the total amount of IL not bound in the wetting layer is located in droplets, and bilayers are only formed to a small extent. From the average footprint and height of the droplets, we can estimate the average volume of IL in the droplets per image. Since we also know the average heights of the $2 \mathrm{D}$ bilayers $(0.71 \mathrm{~nm})$ and the wetting layer $(0.34 \mathrm{~nm})$, we can determine the total IL volume (= sum of the wetting layer, bilayer(s), and droplets) per image. This volume, determined by the statistical analysis of the AFM image after deposition, can be compared to the deposited amount in WLE, derived from our calibrated microbalance. Notably, the accuracy of this comparison is limited by the number of analyzed images, edge effects of the area determination, and the assumption of an ellipsoid-like shape of the droplets (the volume of an ellipsoid is two-thirds of that of a cylinder with an identical footprint). Nevertheless, when assuming an ellipsoid-like shape, the amount determined by the statistical AFM analysis and the deposited amount derived via QCM (indicated by horizontal dashed lines in Figure 5f) agree to within $5-10 \%$, that is, extremely well.

Next, we analyze the statistical evaluation of how the average properties of the droplets (number and diameters, heights, and volumes) and bilayers (volume) shown in Figure 5 develop as a function of time at $250 \mathrm{~K}$ (the graphs containing the underlying data are shown in Figure S3). The number of droplets shows an initial decay, and thereafter stays more or less constant. The droplets continuously decrease in height and diameter, while at the same time the surface area covered with the 2D bilayer increases accordingly. This reflects the transition from the $3 \mathrm{D}$ droplets to the $2 \mathrm{D}$ crystalline bilayer phase. The analysis of the total volume as a function of time shows a decrease of $\sim 20 \%$ over time. This decrease is likely due to a combination of effects, that is, an underestimation of the droplet volume due to transition toward more cylinder-like shaped islands, and the fact that with continued growth of the $2 \mathrm{D}$ phase it becomes more difficult to identify whether multiple bilayers are formed; both effects would lead to an underestimation of the total amount of IL on the surface. We rule out desorption due to the fact that in previous publications we never observed indications of desorption at these temperatures $^{33}$ and that $250 \mathrm{~K}$ is well below the multilayer desorption temperature of $345 \mathrm{~K}$ on the similar $\mathrm{Ag}(111)$ surface. ${ }^{17,35}$ However, while we do not observe an influence by multilayer desorption at $300 \mathrm{~K}$, we cannot fully exclude it at this temperature.

\section{DISCUSSION}

Overall, the morphology of the deposited IL films shows a very complex temperature and time dependence. Nevertheless, our experimental findings by AFM in real space are in good agreement with the general conclusions for the very related systems, that is, a few multilayers of $\left[\mathrm{C}_{1} \mathrm{C}_{1} \mathrm{Im}\right]\left[\mathrm{Tf}_{2} \mathrm{~N}\right]$ on $\mathrm{Ag}(111)$ by Lexow et al. ${ }^{35}$ and $\left[\mathrm{C}_{2} \mathrm{C}_{1} \operatorname{Im}\right]\left[\mathrm{Tf}_{2} \mathrm{~N}\right]$ on $\mathrm{Au}(110)$ 
by Foulston et al. $^{36}$ In both studies, the authors observed changes of substrate- and IL-derived XPS or UPS signals with time after deposition at RT, on the time scale of hours before reaching a plateau. Interestingly, for $\left[\mathrm{C}_{8} \mathrm{C}_{1} \mathrm{Im}\right]\left[\mathrm{Tf}_{2} \mathrm{~N}\right]$ on $\mathrm{Ag}(111)$, time-dependent effects were completely absent upon deposition at RT, indicating that this behavior can strongly depend on the molecular structure.

Our interpretation of the observed behavior in this study follows the overall reasoning proposed by Lexow et al. ${ }^{35}$ but is now based on real-space information derived from AFM, rather than indirect information derived from photoelectron spectroscopy. Indeed, the real-space information revealed that the behavior is even more complex than anticipated from XPS. The change of the $3 \mathrm{D}$ droplets to $2 \mathrm{D}$ bilayers indicates that the 3D droplets are a kinetically stabilized metastable phase, which over time irreversibly transforms into the more stable layered $2 \mathrm{D}$ structure composed of successive bilayers. We attribute the initial formation of $3 \mathrm{D}$ droplets of $\left[\mathrm{C}_{1} \mathrm{C}_{1} \mathrm{Im}\right]\left[\mathrm{Tf}_{2} \mathrm{~N}\right]$ on $\mathrm{Au}(111)$ on top of the closed wetting layer to the existence of different processes with very different time scales. After the impact on the surface at RT, the IL ion pairs are very mobile, diffuse on the surface, and instantaneously agglomerate into 3D droplets. This behavior likely results from the much higher and energetically favored coordination of the individual ions in a $3 \mathrm{D}$ droplet, as compared to isolated ion pairs on the $\mathrm{WL}$. In a similar way, upon fast annealing a disordered IL layer adsorbed at low temperature $(<170 \mathrm{~K})$ to $\mathrm{RT}$, the IL ion pairs agglomerate to $3 \mathrm{D}$ droplets. Both observations are due to the fact that the nucleation of individual ion pairs to large enough, stable $2 \mathrm{D}$ bilayer islands on the wetting layer and their successive growth obviously is too slow to compete on the time scale of $3 \mathrm{D}$ agglomeration. Otherwise, large $2 \mathrm{D}$ bilayer regions should form from the very beginning at RT or during heating. This behavior is attributed to the instability of small 2D bilayer islands, which would serve as nuclei for further $2 \mathrm{D}$ growth. Thus, statistically formed small $2 \mathrm{D}$ bilayer islands disintegrate quickly.

Our experiments in Figure 2 further show that if a RT layer with $3 \mathrm{D}$ droplets is cooled to $110 \mathrm{~K}$ and successively annealed at RT for extended times (hours), or if a low-temperaturedeposited layer is slowly (over days) annealed to room temperature, the formation of the thermodynamically favored $2 \mathrm{D}$ bilayers occurs. Furthermore, the immediate formation of $2 \mathrm{D}$ bilayers at $250 \mathrm{~K}$ indicates that this temperature is favorable for the formation of many $2 \mathrm{D}$ nuclei, which leads to the exclusive $2 \mathrm{D}$ bilayer growth upon deposition at this temperature. In addition, at this temperature, diffusion of the IL on the wetting layer possibly is too slow for the agglomeration of 3D islands. During fast heating of a lowtemperature-deposited disordered IL layer some 2D nuclei are formed, which then continue to grow at a slow rate at RT, which leads to the conversion of the $3 \mathrm{D}$ droplets to the $2 \mathrm{D}$ bilayer over the time period of hours. At $250 \mathrm{~K}$, the conversion of $3 \mathrm{D}$ droplets (formed upon deposition at $300 \mathrm{~K}$ ) occurs at an even slower time scale (days) than at RT (see Figures 4 and 5). The observed slow conversion is attributed to the high activation barrier for the growth of the $2 \mathrm{D}$ bilayers, which is likely related to the detachment/emission of ion pairs from the 3D droplet onto already formed bilayers, or a Schwoebel barrier $^{46}$ for mobile IL ion pairs to hop over the bilayer island edges. In addition, a slow diffusion on the wetting layer and on already formed bilayers might also contribute.
We attribute the stabilization of the $2 \mathrm{D}$ bilayers on the wetting layer and also on already formed crystalline bilayers to the higher degree of order in these layers, which in the case of the wetting layer is indicated by the observation of a longrange-ordered $2 \mathrm{D}$ crystalline phase even at $\mathrm{RT}$, as evidenced by AFM. The proposed metastable nature of the $3 \mathrm{D}$ droplets and the higher stability of the $2 \mathrm{D}$ bilayer phase is also in line with the observed influence of the AFM tip when subsequently scanning the same surface area (see Figure 3), where the transition occurs on a much faster time scale. Interestingly, on a comparable substrate, the $\operatorname{Ag}(111)$ surface, we observe that the transition can also be accelerated to some extent by exposure to X-rays. While initially the influence of radiation on the growth mode was ruled out, ${ }^{35}$ detailed recent experiments for $\left[\mathrm{C}_{1} \mathrm{C}_{1} \mathrm{Im}\right]\left[\mathrm{Tf}_{2} \mathrm{~N}\right]$ show that the transformation occurs significantly slower at lower radiation doses (see Figure S4 in the SI); however, no indications of beam damage were detected, within the detection limit of the measurements. Thus, it seems that X-ray-induced excitations help IL ion pairs to detach from the $3 \mathrm{D}$ islands or to overcome the Schwoebel barrier, in a similar way as observed for the AFM tip. The details of this mechanism are not yet understood.

Within our interpretation, we can also understand that $\left[\mathrm{C}_{8} \mathrm{C}_{1} \mathrm{Im}\right]\left[\mathrm{Tf}_{2} \mathrm{~N}\right]$ does not form $3 \mathrm{D}$ droplets at RT. This behavior is attributed to an enhanced stabilization of IL ion pairs on the wetting layer by attractive van-der-Waals interactions between the alkyl chains of $\left[\mathrm{C}_{8} \mathrm{C}_{1} \mathrm{Im}\right]\left[\mathrm{Tf}_{2} \mathrm{~N}\right]$.

\section{CONCLUSIONS}

We investigated the growth and time evolution of the surface morphology of $\left[\mathrm{C}_{1} \mathrm{C}_{1} \mathrm{Im}\right]\left[\mathrm{Tf}_{2} \mathrm{~N}\right]$ on $\mathrm{Au}(111)$ after deposition in UHV at temperatures below $170 \mathrm{~K}$ followed by annealing to RT and after direct deposition at RT. Our in situ measurements by AFM provide direct real-space information for doses ranging from two to six wetting layer equivalents. Independent of temperature, initially a closed wetting layer is formed. At low temperature, we observe a hit-and-stick adsorption behavior on top of this wetting layer, leading to a disordered weakly corrugated layer. Upon slow annealing to RT, we find, depending on the deposited amount, the formation of one or several 2D bilayers on top of the wetting layer, with heights of $\sim 0.71 \mathrm{~nm}$. In stark contrast, upon deposition at RT or deposition at low temperature followed by short annealing at $\mathrm{RT}$, we observe the formation of $3 \mathrm{D}$ droplets with heights of 2-30 $\mathrm{nm}$, depending on the deposited amount, on top of the wetting layer. Time-dependent AFM measurements at $250 \mathrm{~K}$ reveal the transformation of these droplets to $2 \mathrm{D}$ bilayers on the time scale of hours to days, finally yielding the same morphology as obtained after deposition at low temperature followed by slow annealing to RT. Time-dependent changes of the surface morphology have already been anticipated indirectly from photoelectron spectroscopy in the literature for $\left[\mathrm{C}_{1} \mathrm{C}_{1} \operatorname{Im}\right]\left[\mathrm{Tf}_{2} \mathrm{~N}\right]$ and $\left[\mathrm{C}_{2} \mathrm{C}_{1} \operatorname{Im}\right]\left[\mathrm{Tf}_{2} \mathrm{~N}\right]$ on $\mathrm{Ag}(111)$ and $\mathrm{Au}(110)$, respectively. From our time-dependent real-space AFM measurements, we conclude that upon deposition at RT, $\left[\mathrm{C}_{1} \mathrm{C}_{1} \mathrm{Im}\right]\left[\mathrm{Tf}_{2} \mathrm{~N}\right]$ initially forms large $3 \mathrm{D}$ IL droplets on a very fast time scale because the nucleation of individual ion pairs to stable $2 \mathrm{D}$ bilayer islands on the wetting layer is too slow to compete with $3 \mathrm{D}$ growth. Otherwise, large $2 \mathrm{D}$ bilayer regions should form from the very beginning. The $3 \mathrm{D}$ droplets are a kinetically stabilized metastable phase, which over time transforms into the more stable layered 2D structure composed of successive bilayers, provided enough nuclei for 
condensation are available. This can, for e.g., be achieved by intermediate cooling to lower temperatures. We attribute the stabilization of the $2 \mathrm{D}$ bilayers on the wetting layer and on already formed bilayers to the high degree of order in these layers. Notably, we observe that the transformation process from the 3D droplets to $2 \mathrm{D}$ bilayer islands is accelerated by tip effects and also X-ray radiation. Our study is of great relevance due to the immense application potential of ultrathin IL films, which ranges from innovative concepts in catalysis (SILP, SCILL) and protective layers for reactive interfaces to electrical contacts in nanotechnology.

\section{ASSOCIATED CONTENT}

\section{SI Supporting Information}

The Supporting Information is available free of charge at https://pubs.acs.org/doi/10.1021/acs.jpcc.1c06613.

It contains additional AFM images demonstrating the molecular resolution of the wetting layer and successive bilayers; detailed statistical analysis of the time evolution of three different IL coverages at $250 \mathrm{~K}$; time-dependent $\mathrm{XP}$ spectra of a comparable system, that is, $\left[\mathrm{C}_{1} \mathrm{C}_{1} \mathrm{Im}\right]\left[\mathrm{Tf}_{2} \mathrm{~N}\right]$ on $\mathrm{Ag}(111)$; and detailed information on sample preparation (PDF)

A video showing how $3 \mathrm{D}$ IL droplets are transformed to bilayers at $250 \mathrm{~K}$, as described in Figure 3 (AVI)

\section{AUTHOR INFORMATION}

\section{Corresponding Author}

Hans-Peter Steinrück - Lehrstuhl für Physikalische Chemie

II, Universität Erlangen-Nürnberg, 91058 Erlangen,

Germany; 이이이.org/0000-0003-1347-8962;

Email: hans-peter.steinrueck@fau.de

\section{Authors}

Manuel Meusel - Lehrstuhl für Physikalische Chemie II, Universität Erlangen-Nürnberg, 91058 Erlangen, Germany

Afra Gezmis - Lehrstuhl für Physikalische Chemie II, Universität Erlangen-Nürnberg, 91058 Erlangen, Germany

Simon Jaekel - Lehrstuhl für Physikalische Chemie II, Universität Erlangen-Nürnberg, 91058 Erlangen, Germany

Matthias Lexow - Lehrstuhl für Physikalische Chemie II, Universität Erlangen-Nürnberg, 91058 Erlangen, Germany; ○ orcid.org/0000-0002-1441-2909

Andreas Bayer - Lehrstuhl für Physikalische Chemie II, Universität Erlangen-Nürnberg, 91058 Erlangen, Germany

Florian Maier - Lehrstuhl für Physikalische Chemie II, Universität Erlangen-Nürnberg, 91058 Erlangen, Germany; (1) orcid.org/0000-0001-9725-8961

Complete contact information is available at:

https://pubs.acs.org/10.1021/acs.jpcc.1c06613

\section{Notes}

The authors declare no competing financial interest.

\section{ACKNOWLEDGMENTS}

We thank Nicola Taccardi for the synthesis of $\left[\mathrm{C}_{1} \mathrm{C}_{1} \mathrm{Im}\right]$ $\left[\mathrm{Tf}_{2} \mathrm{~N}\right]$. M.M., A.G., M.L., and H.-P.S. thank the European Research Council (ERC) under the European Union's Horizon 2020 Research and Innovation Programme for financial support, in the context of the Advanced Investigator Grant “ILID" to H.-P.S. (Grant Agreement No. 693398ILID).

\section{REFERENCES}

(1) Zhou, F.; Liang, Y.; Liu, W. Ionic liquid lubricants: designed chemistry for engineering applications. Chem. Soc. Rev. 2009, 38, 2590-2599.

(2) Cooper, P. K.; Staddon, J.; Zhang, S.; Aman, Z. M.; Atkin, R.; Li, H. Nano- and Macroscale Study of the Lubrication of Titania Using Pure and Diluted Ionic Liquids. Front. Chem. 2019, 7, No. 287.

(3) Cooper, P. K.; Wear, C. J.; Li, H.; Atkin, R. Ionic Liquid Lubrication of Stainless Steel: Friction is Inversely Correlated with Interfacial Liquid Nanostructure. ACS Sustainable Chem. Eng. 2017, 5, 11737-11743.

(4) Kondo, Y.; Yagi, S.; Koyama, T.; Tsuboi, R.; Sasaki, S. Lubricity and corrosiveness of ionic liquids for steel-on-steel sliding contacts. Proc. Inst. Mech. Eng., Part J 2012, 226, 991-1006.

(5) Bermúdez, M. D.; Jimenez, A. E.; Sanes, J.; Carrion, F. J. Ionic liquids as advanced lubricant fluids. Molecules 2009, 14, 2888-2908.

(6) Welton, T. Room-Temperature Ionic Liquids. Solvents for Synthesis and Catalysis. Chem. Rev. 1999, 99, 2071-2084.

(7) Binnemans, K. Ionic liquid crystals. Chem. Rev. 2005, 105, 4148-4204.

(8) Wasserscheid, P.; Keim, W. Ionic Liquids-New "Solutions" for Transition Metal Catalysis. Angew. Chem., Int. Ed. 2000, 39, 37723789.

(9) Mehnert, C. P.; Mozeleski, E. J.; Cook, R. A. Supported ionic liquid catalysis investigated for hydrogenation reactions. Chem. Commun. 2002, 3010-3011.

(10) Huang, J.; Jiang, T.; Gao, H.; Han, B.; Liu, Z.; Wu, W.; Chang, Y.; Zhao, G. Pd nanoparticles immobilized on molecular sieves by ionic liquids: heterogeneous catalysts for solvent-free hydrogenation. Angew. Chem., Int. Ed. 2004, 43, 1397-1399.

(11) Hagiwara, H.; Sugawara, Y.; Isobe, K.; Hoshi, T.; Suzuki, T. Immobilization of $\mathrm{Pd}(\mathrm{OAc})(2)$ in ionic liquid on silica: application to sustainable Mizoroki-Heck reaction. Org. Lett. 2004, 6, 2325-2328.

(12) Breitenlechner, S.; Fleck, M.; Müller, T. E.; Suppan, A. Solid catalysts on the basis of supported ionic liquids and their use in hydroamination reactions. J. Mol. Catal. A: Chem. 2004, 214, 175179.

(13) Kernchen, U.; Etzold, B.; Korth, W.; Jess, A. Solid Catalyst with Ionic Liquid Layer (SCILL) - A New Concept to Improve Selectivity Illustrated by Hydrogenation of Cyclooctadiene. Chem. Eng. Technol. 2007, 30, 985-994.

(14) Riisager, A.; Fehrmann, R.; Flicker, S.; van Hal, R.; Haumann, M.; Wasserscheid, P. Very stable and highly regioselective supported ionic-liquid-phase (SILP) catalysis: continuous-flow fixed-bed hydroformylation of propene. Angew. Chem., Int. Ed. 2005, 44, 815-819.

(15) Heinze, M. T.; Zill, J. C.; Matysik, J.; Einicke, W. D.; Gläser, R.; Stark, A. Solid-ionic liquid interfaces: pore filling revisited. Phys. Chem. Chem. Phys. 2014, 16, 24359-24372.

(16) Steinrück, H.-P.; Wasserscheid, P. Ionic Liquids in Catalysis. Catal. Lett. 2015, 145, 380-397.

(17) Lexow, M.; Maier, F.; Steinrück, H. P. Ultrathin ionic liquid films on metal surfaces: adsorption, growth, stability and exchange phenomena. Adv. Phys.: X 2020, 5, No. 1761266.

(18) Syres, K. L.; Jones, R. G. Adsorption, Desorption, and Reaction of 1-Octyl-3-methylimidazolium Tetrafluoroborate, [C(8)C(1) Im][BF(4)], Ionic Liquid Multilayers on $\mathrm{Cu}(111)$. Langmuir 2015, 31, 9799-9808

(19) Costa, J. C. S.; Coelho, A. F. S. M. G.; Mendes, A.; Santos, L. M. N. B. F. Nucleation and growth of microdroplets of ionic liquids deposited by physical vapor method onto different surfaces. Appl. Surf. Sci. 2018, 428, 242-249.

(20) Fu-Chun, Z.; Mao-Lin, S.; Xiu-Ping, R.; Guo-Zhong, W.; Jun, H.; Yi, Z. Morphology and Wettability of [Bmim] [PF6] Ionic Liquid on HOPG Substrate. Chin. Phys. Lett. 2010, 27, No. 086101.

(21) Gong, X.; Wang, B.; Li, L. Spreading of Nanodroplets of Ionic Liquids on the Mica Surface. ACS Omega 2018, 3, 16398-16402.

(22) Delcheva, I.; Ralston, J.; Beattie, D. A.; Krasowska, M. Static and dynamic wetting behaviour of ionic liquids. Adv. Colloid Interface Sci. 2015, 222, 162-171. 
(23) Zhang, G. R.; Munoz, M.; Etzold, B. J. Accelerating OxygenReduction Catalysts through Preventing Poisoning with Non-Reactive Species by Using Hydrophobic Ionic Liquids. Angew. Chem., Int. Ed. 2016, 55, 2257-2261.

(24) Atkin, R.; El Abedin, S. Z.; Hayes, R.; Gasparotto, L. H. S.; Borisenko, N.; Endres, F. AFM and STM Studies on the Surface Interaction of [BMP]TFSA and [EMIm]TFSA Ionic Liquids with $\mathrm{Au}(111)$. J. Phys. Chem. C 2009, 113, 13266-13272.

(25) Endres, F.; Borisenko, N.; El Abedin, S. Z.; Hayes, R.; Atkin, R. The interface ionic liquid(s)/electrode(s): in situ STM and AFM measurements. Faraday Discuss. 2012, 154, 221-233.

(26) Zhang, X.; Zhong, Y. X.; Yan, J. W.; Su, Y. Z.; Zhang, M.; Mao, B. W. Probing double layer structures of Au (111)-BMIPF6 ionic liquid interfaces from potential-dependent AFM force curves. Chem. Commun. 2012, 48, 582-584.

(27) Lovelock, K. R.; Kolbeck, C.; Cremer, T.; Paape, N.; Schulz, P. S.; Wasserscheid, P.; Maier, F.; Steinrück, H. P. Influence of different substituents on the surface composition of ionic liquids studied using ARXPS. J. Phys. Chem. B 2009, 113, 2854-2864.

(28) Lovelock, K. R.; Villar-Garcia, I. J.; Maier, F.; Steinrück, H. P.; Licence, P. Photoelectron spectroscopy of ionic liquid-based interfaces. Chem. Rev. 2010, 110, 5158-5190.

(29) Cremer, T.; Stark, M.; Deyko, A.; Steinrück, H. P.; Maier, F. Liquid/solid interface of ultrathin ionic liquid films: [C1C1Im][Tf $2 \mathrm{~N}]$ and $[\mathrm{C} 8 \mathrm{C} 1 \mathrm{Im}][\mathrm{Tf} 2 \mathrm{~N}]$ on $\mathrm{Au}(111)$. Langmuir 2011, 27, $3662-3671$.

(30) Steinrück, H. P.; Libuda, J.; Wasserscheid, P.; Cremer, T.; Kolbeck, C.; Laurin, M.; Maier, F.; Sobota, M.; Schulz, P. S.; Stark, M. Surface science and model catalysis with ionic liquid-modified materials. Adv. Mater. 2011, 23, 2571-2587.

(31) Yoshimura, D.; Yokoyama, T.; Nishi, T.; Ishii, H.; Ozawa, R.; Hamaguchi, H.; Seki, K. Electronic structure of ionic liquids at the surface studied by UV photoemission. J. Electron Spectrosc. Relat. Phenom. 2005, 144-147, 319-322.

(32) Meusel, M.; Lexow, M.; Gezmis, A.; Schötz, S.; Wagner, M.; Bayer, A.; Maier, F.; Steinrück, H. P. Atomic Force and Scanning Tunneling Microscopy of Ordered Ionic Liquid Wetting Layers from $110 \mathrm{~K}$ up to Room Temperature. ACS Nano 2020, 14, 9000-9010.

(33) Meusel, M.; Lexow, M.; Gezmis, A.; Bayer, A.; Maier, F.; Steinrück, H. P. Growth of Multilayers of Ionic Liquids on $\mathrm{Au}(111)$ Investigated by Atomic Force Microscopy in Ultrahigh Vacuum. Langmuir 2020, 36, 13670-13681.

(34) Uhl, B.; Huang, H.; Alwast, D.; Buchner, F.; Behm, R. J. Interaction of ionic liquids with noble metal surfaces: structure formation and stability of [OMIM][TFSA] and [EMIM][TFSA] on $\mathrm{Au}(111)$ and $\operatorname{Ag}(111)$. Phys. Chem. Chem. Phys. 2015, 17, 2381623832.

(35) Lexow, M.; Talwar, T.; Heller, B. S. J.; May, B.; Bhuin, R. G.; Maier, F.; Steinrück, H. P. Time-dependent changes in the growth of ultrathin ionic liquid films on $\operatorname{Ag}(111)$. Phys. Chem. Chem. Phys. 2018, 20, 12929-12938.

(36) Foulston, R.; Gangopadhyay, S.; Chiutu, C.; Moriarty, P.; Jones, R. G. Mono- and multi-layer adsorption of an ionic liquid on $\mathrm{Au}(110)$. Phys. Chem. Chem. Phys. 2012, 14, 6054-6066.

(37) Rietzler, F.; May, B.; Steinrück, H. P.; Maier, F. Switching adsorption and growth behavior of ultrathin [C2C1Im] [OTf] films on $\mathrm{Au}(111)$ by Pd deposition. Phys. Chem. Chem. Phys. 2016, 18, 25143-25150.

(38) Cremer, T.; Killian, M.; Gottfried, J. M.; Paape, N.; Wasserscheid, P.; Maier, F.; Steinrück, H. P. Physical vapor deposition of $[\mathrm{EMIm}][\mathrm{Tf} 2 \mathrm{~N}]$ : a new approach to the modification of surface properties with ultrathin ionic liquid films. ChemPhysChem 2008, 9, 2185-2190.

(39) Deyko, A.; Cremer, T.; Rietzler, F.; Perkin, S.; Crowhurst, L.; Welton, T.; Steinrück, H.-P.; Maier, F. Interfacial Behavior of Thin Ionic Liquid Films on Mica. J. Phys. Chem. C 2013, 117, 5101-5111.

(40) Cremer, T.; Wibmer, L.; Krick Calderón, S.; Deyko, A.; Maier, F.; Steinrück, H. P. Interfaces of ionic liquids and transition metal surfaces-adsorption, growth, and thermal reactions of ultrathin
$[\mathrm{C} 1 \mathrm{C} 1 \mathrm{Im}][\mathrm{Tf} 2 \mathrm{~N}]$ films on metallic and oxidised $\mathrm{Ni}(111)$ surfaces. Phys. Chem. Chem. Phys. 2012, 14, 5153-5163.

(41) Lexow, M.; Heller, B. S. J.; Partl, G.; Bhuin, R. G.; Maier, F.; Steinrück, H. P. Cation Exchange at the Interfaces of Ultrathin Films of Fluorous Ionic Liquids on $\mathrm{Ag}(111)$. Langmuir 2019, 35, 398-405.

(42) Miller, S. F.; Friedrich, H. B.; Holzapfel, C. W. The Effects of SCILL Catalyst Modification on the Competitive Hydrogenation of 1-Octyne and 1,7-Octadiene versus 1-Octene. Chem CatChem 2012, 4, 1337-1344.

(43) Reyna-González, J. M.; Reyes-López, J. C.; Aguilar-Martínez, M. Silver and silver-copper electrodeposition from a pyridiniumbased ionic liquid. Electrochim. Acta 2013, 94, 344-352.

(44) Lexow, M.; Heller, B. S. J.; Maier, F.; Steinrück, H. P. Anion Exchange at the Liquid/Solid Interface of Ultrathin Ionic Liquid Films on $\mathrm{Ag}(111)$. ChemPhysChem 2018, 19, 2978-2984.

(45) Horcas, I.; Fernandez, R.; Gomez-Rodriguez, J. M.; Colchero, J.; Gomez-Herrero, J.; Baro, A. M. WSxM: a software for scanning probe microscopy and a tool for nanotechnology. Rev. Sci. Instrum. 2007, 78, No. 013705.

(46) Schwoebel, R. L.; Shipsey, E. J. Step Motion on Crystal Surfaces. J. Appl. Phys. 1966, 37, 3682-3686. 